\title{
Ultrafast Light-Driven Electron Transfer in a Ru(II)tris(bipyridine)- Labeled Multiheme Cytochrome
}

\author{
Jessica H. van Wonderen, ${ }^{\dagger, \perp}$ Christopher R. Hall, ${ }^{\dagger, \nabla, \perp \odot}$ Xiuyun Jiang, $^{\dagger, \perp}$ Katrin Adamczyk, $^{\dagger, \perp}$
} Antoine Carof, ${ }^{\ddagger, \wedge}$ Ismael Heisler, ${ }^{\dagger, \# \odot ~ S a m u e l ~ E . ~ H . ~ P i p e r, ~}{ }^{\dagger}$ Thomas A. Clarke, ${ }^{\dagger}$ Nicholas J. Watmough, ${ }^{\dagger}$ Igor V. Sazanovich, ${ }^{\S}$ Michael Towrie, ${ }^{\S}$ Stephen R. Meech, ${ }^{*}, \oplus$ Jochen Blumberger, ${ }^{*},+, \|_{\odot}$ and Julea N. Butt* ${ }^{\dagger} \odot$

\begin{abstract}
${ }^{\dagger}$ School of Chemistry and School of Biological Sciences, University of East Anglia, Norwich Research Park, Norwich NR4 7TJ, United Kingdom

${ }^{\ddagger}$ Department of Physics and Astronomy and Thomas-Young Centre, University College London, London WC1E 6BT, United Kingdom

${ }^{\S}$ Central Laser Facility, Research Complex at Harwell, Harwell Campus, Didcot, Oxon OX11 0QX, United Kingdom

"Institute for Advanced Study, Technische Universität München, Lichtenbergstrasse 2 a, D-85748 Garching, Germany
\end{abstract}

Supporting Information

\begin{abstract}
Multiheme cytochromes attract much attention for their electron transport properties. These proteins conduct electrons across bacterial cell walls and along extracellular filaments and when purified can serve as bionanoelectronic junctions. Thus, it is important and necessary to identify and understand the factors governing electron transfer in this family of proteins. To this end we have used ultrafast transient absorbance spectroscopy, to define heme-heme electron transfer dynamics in the representative multiheme cytochrome STC from Shewanella oneidensis in aqueous solution. STC was photosensitized by site-selective labeling with a $\mathrm{Ru}(\mathrm{II})$ (bipyridine) $)_{3}$ dye and the dynamics of light-driven electron transfer described by a kinetic model corroborated by molecular dynamics simulation and density functional theory calculations. With
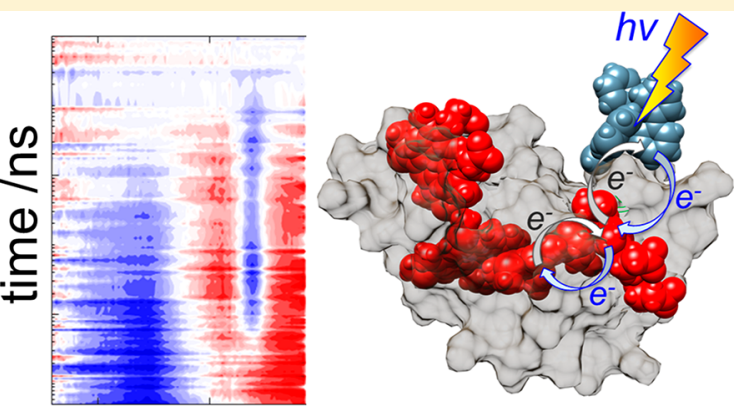

$\lambda / \mathrm{nm}$ the dye attached adjacent to STC Heme IV, a rate constant of $87 \times 10^{6} \mathrm{~s}^{-1}$ was resolved for Heme IV $\rightarrow$ Heme III electron transfer. With the dye attached adjacent to STC Heme I, at the opposite terminus of the tetraheme chain, a rate constant of 125 $\times 10^{6} \mathrm{~s}^{-1}$ was defined for Heme I $\rightarrow$ Heme II electron transfer. These rates are an order of magnitude faster than previously computed values for unlabeled STC. The Heme III/IV and I/II pairs exemplify the T-shaped heme packing arrangement, prevalent in multiheme cytochromes, whereby the adjacent porphyrin rings lie at $90^{\circ}$ with edge-edge $(\mathrm{Fe}-\mathrm{Fe})$ distances of $\sim 6$ (11) A. The results are significant in demonstrating the opportunities for pump-probe spectroscopies to resolve interheme electron transfer in Ru-labeled multiheme cytochromes.
\end{abstract}

\section{INTRODUCTION}

Species of Shewanella attract much interest for their ability to respire in the absence of oxygen by transferring electrons from intracellular oxidation of organic matter to extracellular acceptors including $\mathrm{Fe}_{2} \mathrm{O}_{3}$ and $\mathrm{MnO}_{2}$ nanoparticles. ${ }^{1,2}$ Multiheme cytochromes are essential to this process, and these fascinating proteins are spanned by chains of close-packed $c$ type hemes. Intra- and intercytochrome electron transfer occurs by complementary $\mathrm{Fe}(\mathrm{III}) \leftrightarrow \mathrm{Fe}(\mathrm{II})$ transitions of neighboring sites ${ }^{3-5}$ and in this way electrons are moved from the inner bacterial membrane, across the periplasm and outer membrane lipid bilayer to reach the cell exterior. Multiheme cytochromes also contribute to the conductivity of extracellular structures, often termed bacterial nanowires, which transfer electrons across distances greatly exceeding cellular dimensions. These structures for Shewanella oneidensis are multiheme cytochrome containing extensions of the bacterial outer membrane $^{6}$ and for Geobacter sulfurreducens are filaments ${ }^{7,8}$ comprised of a polymerized multiheme cytochrome. Beyond their biological role, the remarkable electron transfer properties of multiheme cytochromes have stimulated interest in these proteins as novel bioelectronic junctions and devices. ${ }^{9-12}$ Furthermore, these proteins underpin the wiring of bacteria to electrodes ${ }^{1,13-15}$ to produce electricity in mediator-less microbial fuel cells and valued chemicals by microbial electrosynthesis. It is now important to identify the factors governing electron transfer in this family of proteins to both understand biology and inspire advances in new, and yet to be conceived, biotechnology.

Received: June 28, 2019

Published: August 27, 2019 
Multiheme cytochromes are defined by the presence of close-packed $c$-type hemes, typically with $\mathrm{His} / \mathrm{His}$ axial ligation, arranged in similar configurations despite very different amino acid sequences and protein folds. ${ }^{3}$ Two heme-packing motifs, namely T-shaped and stacked, predominate in the structures resolved to date. Both motifs are present in the periplasmic cytochrome STC ${ }^{16}$ from $S$. oneidensis that is spanned by a chain of four His/His ligated hemes, Figure 1.

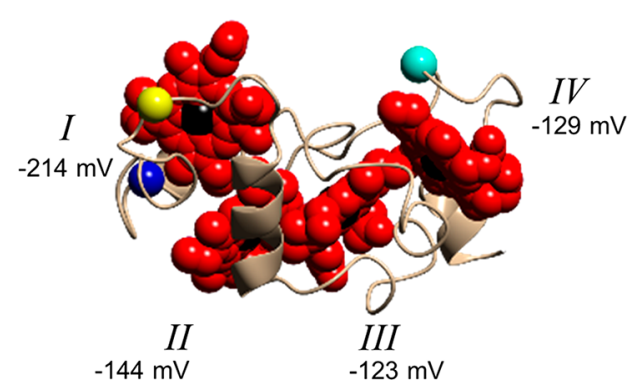

Figure 1. STC of S. oneidensis illustrating the four hemes (red) and their microscopic reduction potentials $\mathrm{s}^{28}$ in the all-oxidized protein. The $\mathrm{C}_{\alpha}$ atoms of residues changed to Cys for labeling with a $\mathrm{Ru}(\mathrm{II})$ dye photosensitizer are indicated as spheres: residues 10 (blue), 23 (yellow), and 77 (cyan).

Heme pairs I/II and III/IV exemplify the T-shaped geometry of neighbors with perpendicular porphyrin rings and edgeedge $(\mathrm{Fe}-\mathrm{Fe})$ distances of 5-8 $(11-12)$ A. The STC heme II/III pair exemplifies the stacked packing motif with parallel porphyrin rings in van der Waals contact and a shorter edgeedge $(\mathrm{Fe}-\mathrm{Fe})$ distance of $\sim 4(\sim 9) \AA$. The possibility that these geometries are optimized to impose control over electron transfer rates and direction has been explored at a singleprotein level through quantum chemistry and molecular simulation. ${ }^{17-21}$ However, to the best of our knowledge, direct measurements of heme-heme electron transfer rates have yet to be reported for STC or other multiheme cytochromes. As a consequence we were motivated to establish whether pumpprobe spectroscopy could provide experimental insight into STC heme-heme electron transfer dynamics and, in turn, inform discussions surrounding the mechanism of electron transfer in multiheme cytochromes.

Pump-probe spectroscopies, through appropriate combinations of light-triggered electron transfer and time-resolved spectroscopy, offer a powerful way to resolve pathways and dynamics of protein electron transfer across time scales ranging from pico- to milli-seconds. ${ }^{22-25}$ The heme-heme electron transfer rate constants in solvated STC are calculated ${ }^{18}$ to range from $\sim 0.5-200 \times 10^{6} \mathrm{~s}^{-1}$ and in previous work ${ }^{9}$ we established that STC could be labeled site-selectively with [ Ru(II) (4-bromomethyl-4'-methylbipyridine) (bipyridine $\left.)_{2}\right]^{2+}$, a thiol-reactive phototrigger of electron transfer. $^{22,26,27}$ Following photoexcitation into the Ru-dye metalto-ligand charge transfer (MLCT) band, the triplet excited state was oxidatively quenched by heme reduction. ${ }^{9}$ Such electron transfer, Scheme 1, pathway $1,\left(E_{\mathrm{m}} \mathrm{Ru}(\mathrm{III}) /(\mathrm{II} *) \approx\right.$ $-870 \mathrm{mV}$ vs $\left.\mathrm{SHE}^{26}\right)$, produces a charge separated state, $\mathrm{Ru}^{+}: \mathrm{STC}^{-}$, that will return to the $\mathrm{Ru}: \mathrm{STC}$ ground state by charge recombination, Scheme 1, pathway $2,\left(E_{\mathrm{m}} \mathrm{Ru}(\mathrm{III}) /(\mathrm{II})\right.$ $\left.\approx 1270 \mathrm{mV}^{26}\right)$. However, heme-heme electron transfer in $\mathrm{Ru}^{+}: \mathrm{STC}^{-}$could result in each heme existing transiently as $\mathrm{Fe}(\mathrm{II})$; the corresponding microscopic $E_{\mathrm{m}}$ values ${ }^{28}$ lie between -120 and $-215 \mathrm{mV}$ as summarized in Figure 1. Gaining direct
Scheme 1

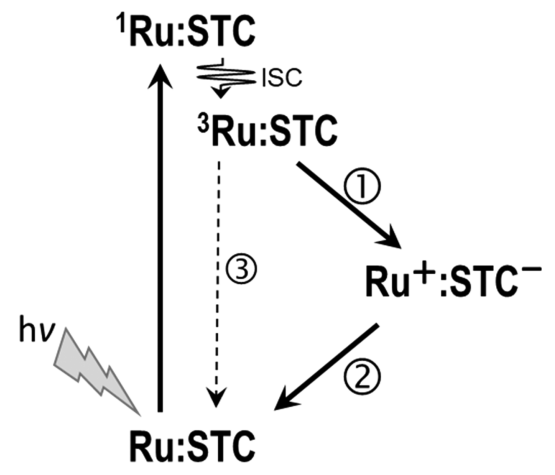

spectroscopic evidence for electron transfer along the heme wire will be challenging due to the chemical similarity of the hemes. However, we reasoned that heme-heme electron transfer will influence the dynamics of the corresponding photocycle in a manner that could be resolved by ultrafast pump-probe spectroscopy given the time scales predicted for heme-heme electron transfer and lack of protein superstructure, that will inevitably place the $\mathrm{Ru}(\mathrm{II})$-dye in close proximity to the acceptor heme leading to fast charge separation and recombination rates.

Here we present ultrafast transient absorbance (TA) of STC proteins photosensitized to inject an electron into opposite ends of the tetraheme chain, into either Heme I or Heme IV as illustrated in Figure 1. Kinetic modeling of the electron transfer dynamics, corroborated by molecular dynamics (MD) simulations and density functional theory (DFT) calculations that provide a microscopic view of the contributing processes, allows us to present rate constants for Heme I $\leftrightarrow$ Heme II and Heme IV $\leftrightarrow$ Heme III electron transfer that are indicative of fast heme-to-heme electron transfer on the $10 \mathrm{~ns}$ time scale. The results are significant in demonstrating the opportunities for pump-probe spectroscopies to resolve interheme electron transfer in Ru-labeled multiheme cytochromes.

\section{EXPERIMENTAL METHODS}

Sample Details. $\mathrm{Ru}(\mathrm{II})$ (4-bromomethyl-4'-methylbipyridine) (bipyridine $)_{2}\left(\mathrm{PF}_{6}\right)_{2}$ (HetCat Switzerland) was prepared as previously described. ${ }^{27}$ All other reagents were analytical grade and aqueous solutions prepared with water having resistivity $>18 \mathrm{M} \Omega \mathrm{cm}$. Preparation of the STC variants A10C, T23C and S77C and of their photosensitized forms, here termed $\mathrm{Ru}_{10}: \mathrm{STC}, \mathrm{Ru}_{23}: \mathrm{STC}$, and $\mathrm{Ru}_{77}:$ STC respectively, was as previously described ${ }^{9}$ and outlined in the Supporting Information. Protein concentrations were defined by electronic absorbance of the tetra-Fe(III) forms using $\varepsilon_{407 \mathrm{~nm}}=422$ $\mathrm{mM}^{-1} \mathrm{~cm}^{-1}$ or $\varepsilon_{552 \mathrm{~nm}}=29.1 \mathrm{mM}^{-1} \mathrm{~cm}^{-1}$ as reported by Leys et al. ${ }^{16}$ TA measurements were performed with anaerobic solutions containing $20 \mathrm{mM}$ TRIS- $\mathrm{HCl}, 0.1 \mathrm{M} \mathrm{NaCl}$ at $\mathrm{pH} 8.5$ and in the absence of sacrificial redox partners. All hemes were in the oxidized, i.e. Fe(III) state, prior to irradiation. Measurements were performed at two protein concentrations to ensure equally good signal-to-noise ratios for quantitative analysis at each wavelength of interest; $\sim 20 \mu \mathrm{M}$ protein for 369 and $419 \mathrm{~nm}$ and $\sim 160 \mu \mathrm{M}$ protein for the less intense features at 453 and $552 \mathrm{~nm}$. The weight-average molecular mass and oligomeric state of $\mathrm{Ru}_{77}: \mathrm{STC}$ in solutions of $20 \mathrm{mM}$ TRIS-HCl, $0.1 \mathrm{M}$ $\mathrm{NaCl}$ at $\mathrm{pH} 8.5$ was defined by analytical ultracentrifugation, sedimentation equilibrium analysis, using a Beckman Optima XL-1 analytical ultracentrifuge equipped with scanning absorbance optics and a Ti50 rotor. Analytical gel filtration was performed with a Superose 6 Increase 10/300 column (GE Healthcare).

Time-Resolved Multiple-Probe Spectroscopy (TRMPS). TRMPS TA was performed at the Central Laser Facility of the 
Rutherford Appleton Laboratory using the apparatus described previously. ${ }^{29,30}$ Excitation was at $457 \mathrm{~nm}$ with $100 \mathrm{fs}$ pulses of 400 $\mathrm{nJ}$ at $1 \mathrm{kHz}$ focused to a spot size of $200 \mu \mathrm{m}$ FWHM. The experiment employed two synchronized ultrafast lasers, one operating at $1 \mathrm{kHz}$ for excitation and one at $10 \mathrm{kHz}$ (the probe), arranged such that for every pump pulse ten probe spectra are collected and pump-probe time delays between $200 \mathrm{fs}$ and $1 \mathrm{~ms}$ are accessible. TA difference spectra were recorded using a white light continuum generated in $\mathrm{CaF}_{2}$, with alternate pump pulses blocked by a chopper. Samples were rastered in the beam to ensure a fresh spot was irradiated by each pump pulse. Further details of the data collection and full details of the data processing are provided in the Supporting Information.

Model Fitting for Electron Transfer Dynamics. As explained in the Results section, the TA signals were fit to two types of kinetic models shown in Schemes 2-4. The time-dependent populations for

\section{Scheme 2}

$$
\left[{ }^{3} \mathrm{Ru}_{y}: \mathrm{STC}_{x} \stackrel{k_{\mathrm{CS}}^{\mathrm{x}}}{\longrightarrow} \mathrm{Ru}_{y}^{+}: \mathrm{STC}_{x}^{-} \stackrel{k_{\mathrm{CR}}^{\mathrm{x}}}{\longrightarrow} \mathrm{Ru}_{y}: \mathrm{STC}_{\mathrm{x}}\right]_{x=a, b, c, d, \ldots . .}
$$

the species in Scheme 2, where $y$ indicates the Ru-dye attachment site, are given by

$$
\begin{aligned}
& p\left({ }^{3} \mathrm{Ru}_{\mathrm{y}}: \mathrm{STC}\right)=\sum_{x} p_{0, x} \mathrm{e}^{-k_{\mathrm{CS}}^{x}} \\
& p\left(\mathrm{Ru}_{\mathrm{y}}^{+}: \mathrm{STC}^{-}\right)=\sum_{x} p_{0, x} \cdot k_{\mathrm{CS}}^{x}\left(\mathrm{e}^{-k_{\mathrm{CS}}^{x} t}-\mathrm{e}^{-k_{\mathrm{CR}}^{x} t}\right) /\left(k_{\mathrm{CR}}^{x}-k_{\mathrm{CS}}^{x}\right) \\
& p\left(\mathrm{Ru}_{\mathrm{y}}: \mathrm{STC}\right)=\sum_{x} p_{0, x} \cdot\left(1+\frac{\left(k_{\mathrm{CS}}^{x} \mathrm{e}^{-k_{\mathrm{CR}}^{x} t}-k_{\mathrm{CR}}^{x} \mathrm{e}^{-k_{\mathrm{CS}}^{x}}\right)}{\left(k_{\mathrm{CR}}^{x}-k_{\mathrm{CS}}^{x}\right)}\right)
\end{aligned}
$$

and $\sum_{x} p_{0, x}=1$, where $p_{0, x}$ is the initial triplet state concentration of $\mathrm{Ru}_{y}:$ STC conformer $x$. Three such models were considered comprised of $2(x=\boldsymbol{a}, \boldsymbol{b}), 3(x=\boldsymbol{a}, \boldsymbol{b}, \boldsymbol{c})$ and $4(x=\boldsymbol{a}, \boldsymbol{b}, \boldsymbol{c}, \boldsymbol{d})$ distinct conformers. For each model the set of rate constants $k_{\mathrm{CS}}^{x}, k_{\mathrm{CR}}^{x}$ and the initial concentrations of each conformer $p_{0, x}$ were determined from best simultaneous fits of the experimental populations to eqs 1 and 2 , see the Supporting Information for details on the fitting procedure. With regard to the refined kinetic model of Scheme 3 including electron

\section{Scheme 3}

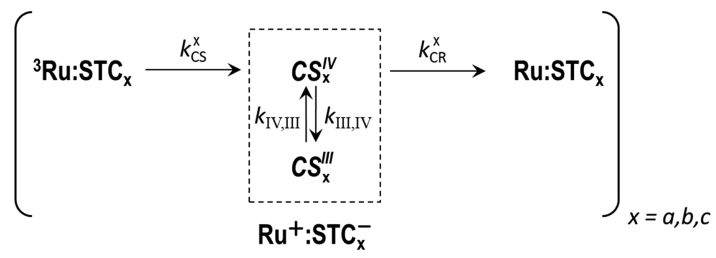

transfer from Heme IV to Heme III of $\mathrm{Ru}_{77}: \mathrm{STC}$, the set of kinetic rate eqs $4-7$,

$$
\begin{aligned}
& \mathrm{d}\left(p\left({ }^{3} \mathrm{Ru}_{77}: \mathrm{STC}_{x}\right)\right) / \mathrm{d} t=-k_{\mathrm{CS}}^{x} p\left({ }^{3} \mathrm{Ru}_{77}: \mathrm{STC}_{x}\right) \\
& \mathrm{d}\left(p\left(\mathrm{CS}_{x}^{\mathrm{IV}}\right)\right) / \mathrm{d} t= k_{\mathrm{CS}}^{x} p\left({ }^{3} \mathrm{Ru}_{77}: \mathrm{STC}_{x}\right)+k_{\mathrm{IV}, \mathrm{III}} p\left(\mathrm{CS}_{x}^{\mathrm{III}}\right) \\
&-\left(k_{\mathrm{III}, \mathrm{IV}}+k_{\mathrm{CR}}^{x}\right) p\left(\mathrm{CS}_{x}^{\mathrm{IV}}\right) \\
& \mathrm{d}\left(p\left(\mathrm{CS}_{x}^{\mathrm{III}}\right)\right) / \mathrm{d} t= k_{\mathrm{III}, \mathrm{IV}} p\left(\mathrm{CS}_{x}^{\mathrm{IV}}\right)-k_{\mathrm{IV}, \mathrm{III}} p\left(\mathrm{CS}_{x}^{\mathrm{III}}\right) \\
& \mathrm{d}\left(p\left(\mathrm{Ru}_{77}: \mathrm{STC}_{x}\right)\right) / \mathrm{d} t=k_{\mathrm{CR}}^{x} p\left(\mathrm{CS}_{x}^{\mathrm{IV}}\right)
\end{aligned}
$$

were solved analytically for a given set of rate constants and initial concentrations. The rate constant $k_{\mathrm{IV}, \mathrm{III}}$ was determined by $k_{\mathrm{IIIIV}}$ and the driving force for electron transfer assuming detailed balance, $k_{\mathrm{IV}, \mathrm{III}}$ $=k_{\mathrm{III}, \mathrm{IV}} \mathrm{e}^{-\mathrm{F}\left(\epsilon_{\mathrm{III}}(\mathrm{O})-\epsilon_{\mathrm{IV}}(\mathrm{O})\right) / k_{\mathrm{B}} T}=k_{\mathrm{III}, \mathrm{IV}} 0.79$ at $T=300 \mathrm{~K}$, where $\epsilon_{i}(\mathrm{O})$ are the reduction potentials of heme $i$ in the all-oxidized $(\mathrm{O})$ state of the protein, taken from experiment ${ }^{28}$ and $F$ is the Faraday constant. Hence, only one additional fitting parameter, $k_{\text {III,IV }}$, was added to the multiple conformer models of Scheme 2. The best set of fit parameters was determined using the same fitting procedure as for the models for Scheme 2. Equivalent equations and processes were used to account for Scheme 4 in providing descriptions of electron transfer between Hemes I and II of $\mathrm{Ru}_{10}$ :STC and $\mathrm{Ru}_{23}$ :STC.

\section{Scheme 4}

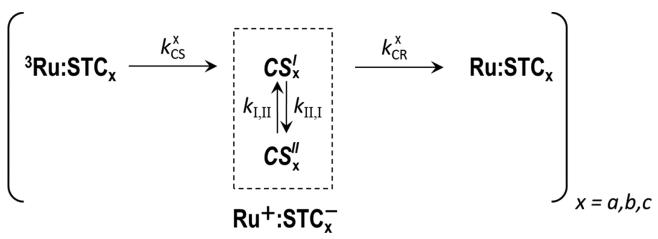

Atomistic Description of Electron Transfer Dynamics in $\mathbf{R u}_{77}$ :STC. For docking of the Ru-dye, the structure ${ }^{16}$ of the native STC protein (1M1Q) was prepared in the all-oxidized state as described in our previous work ${ }^{18}$ except where indicated otherwise. All protein residues are in the standard protonation states at $\mathrm{pH}=7$ except one propionate from Heme III, which is protonated. Serine residue 77 was replaced by a cysteine and the hydrogen atom of $\mathrm{S}-\mathrm{H}$ by $\mathrm{Ru}(\text { bpy })_{2}\left(4-\mathrm{CH}_{2}-4^{\prime}\right.$-methylbipyridine). The docking of the label was performed by sampling the three dihedral angles $\tau_{1}, \tau_{2}$, and $\tau_{3}$, defined in Figure $7 \mathrm{~A}$, between $0^{\circ}$ to $360^{\circ}$ in increments of $5^{\circ}$. In this way more than 100000 trial structures were generated. All structures were energy minimized and clustered with respect to the dihedral angles, see Figure S9, resulting in a total of four unique low-energy clusters termed in the following as conformers $1,2,3$, and 4 . These four conformers were used as initial structures for $\mathrm{MD}$ simulations employing the AMBER03 protein force field, ${ }^{31}$ TIP3P water ${ }^{32}$ and the force field parameters for the Ru-label from our previous work. ${ }^{33}$ The conformers were solvated with a shell of $15 \AA$ of water with $\mathrm{Na}^{+}$and $\mathrm{Cl}^{-}$counterions added to correspond to an ionic strength of $0.1 \mathrm{M}$. After equilibration in the ground electronic state $\left(\mathrm{Ru}^{2+}\right.$, all hemes $\mathrm{Fe}^{3+}$ ) to $300 \mathrm{~K}$ and 1.013 bar (MD time step $=2 \mathrm{fs}$ ), MD production runs were carried out for $100 \mathrm{~ns}$ in the NPT ensemble, for each conformer. Equilibrated configurations from these runs were taken to initialize MD simulations in the $C S^{I V}$ state of $\mathrm{Ru}_{77}^{+}: \mathrm{STC}^{-}\left(\mathrm{Ru}^{3+}\right.$, Heme IV $\mathrm{Fe}^{2+}$, all other hemes $\mathrm{Fe}^{3+}$ ). After equilibration to $300 \mathrm{~K}$ and 1.013 bar, $20 \mathrm{~ns} \mathrm{MD}$ production runs were carried out for each conformer. Average dihedrals and Ru label-Heme IV distances are summarized in Table S5.

Rate constants for charge separation and recombination were calculated using semiclassical electron transfer theory. Electronic coupling matrix elements were calculated using the fragment-orbital density functional theory (FODFT) method implementation ${ }^{34,35}$ in the CPMD package ${ }^{36}$ and the PBE exchange correlation functional. ${ }^{37}$ Coupling matrix elements for charge separation were calculated along the trajectories in state $\mathrm{Ru}_{77}$ :STC for each conformer. The triplet ${ }^{3} \mathrm{MLCT}$ orbital ${ }^{38}$ of the $\mathrm{Ru}$ (II)-label was selected to couple with the two (quasi-)degenerate frontier orbitals of Heme IV, which are composed of the Fe-d $\left(t_{2 \mathrm{~g}}\right)$ and heme ring orbitals. For charge recombination, couplings were calculated along the trajectories in state $\mathrm{Ru}^{+}: \mathrm{STC}^{-}$between the two (quasi-) degenerate frontier orbitals of Heme IV and the highest occupied orbital of the label, composed of Ru-d $\left(t_{2 g}\right)$-bpy ring orbitals, see Figure S12. The FODT couplings for each of the two orbital pairs were square-averaged to an effective coupling matrix element using a similar approach to that previously described $^{18,19}$ and scaled by a factor of 1.348 as recommended in an ab initio benchmark study. ${ }^{39}$ The QM models used for these calculations are detailed in the Supporting Information. Reorganization free energies were obtained as half of the Stokes shift ${ }^{40,41}$ obtained by calculating the vertical electron transfer energy along the trajectories in $\mathrm{Ru}_{77}: \mathrm{STC}$ and $\mathrm{Ru}_{77}^{+}: \mathrm{STC}^{-}$states for each conformer. The outer-sphere reorganization free energy was scaled as 
recommended ${ }^{17}$ to account for the missing electronic polarizability of this force field. Moreover, a nonergodicity correction to the reorganization free energy was applied as recommended ${ }^{42}$ to account for the ultrafast time-scale of the experiments described here. To this end we applied the self-consistent iteration scheme suggested previously, ${ }^{17}$ where the outer-sphere contributions that are slower than the actual electron transfer event are removed, see Figure S11. The inner-sphere contribution was obtained from the usual 4-point scheme using DFT and the PBE functional. Driving forces were taken from experiment. ${ }^{26,28}$ All electron transfer parameters and rate constants for the four conformers are summarized in Table S6. Full details on docking, $\mathrm{MD}$ simulations, and calculation of electron transfer parameters can be found in the Supporting Information.

\section{RESULTS}

In the following sections we first present a detailed account of our studies of $\mathrm{Ru}_{77}: \mathrm{STC}$ where the $\mathrm{Ru}$-dye lies adjacent to Heme IV, Figure 1. Features in the TA are assigned to states within the photocycle of Scheme 1 and their transient populations accurately reproduced by a kinetic model that extends Scheme 1 to include electron transfer across the Heme IV $\leftrightarrow$ Heme III pair. The kinetic model is validated by comparison to the predictions from atomistic descriptions of the protein and corresponding electron transfer dynamics. Finally TA of proteins having the Ru-dye adjacent to Heme I, $\mathrm{Ru}_{23}$ :STC and $\mathrm{Ru}_{10}: \mathrm{STC}$, is presented and interpreted through an equivalent model to define rate constants for electron transfer across the Heme I $\leftrightarrow$ Heme II pair.

In the text below we use $\left[\mathrm{Ru}(\mathrm{bpy})_{3}\right]^{2+}$ to refer to the ground state of the thiol-reactive photosensitizer $[\mathrm{Ru}(\mathrm{II})$ (4-bromomethyl-4'-methylbipyridine)(bpy $\left.)_{2}\right]^{2+}$. The ground state of the photosensitizer attached to S77C STC, adjacent to Heme IV, is termed $\left[\mathrm{Ru}(\mathrm{bpy})_{3}\right]_{\mathrm{STC} 77}^{2+}$ and an equivalent nomenclature describes the Ru-dye labeled STC proteins with cysteine at positions 10 and 23, adjacent to Heme I.

Photoexcitation of $\mathrm{Ru}_{77}:$ STC. The ground state absorbance of $\mathrm{Ru}_{77}: \mathrm{STC}$, Figure $2 \mathrm{~A}$ blue lines, is well described ${ }^{9}$ by superposition of the spectra for S77C STC and $\left[\mathrm{Ru}(\mathrm{bpy})_{3}\right]^{2+}$ in a 1:1 ratio. The dominant features arise from $\pi-\pi^{*}$ transitions of the $\mathrm{Fe}$ (III) hemes; the maximum of the Soretband occurs at $408 \mathrm{~nm}$ and of the $\alpha-/ \beta$-band at $524 \mathrm{~nm}$. The hemes also have significant absorbance at $453 \mathrm{~nm}$ where the MLCT band ${ }^{43}$ of the $\mathrm{Ru}(\mathrm{II})$-dye is centered, Figure $2 \mathrm{~A}$ red line. As a consequence, exciting the dye MLCT band by pulsed irradiation of $\mathrm{Ru}_{77}: \mathrm{STC}$ at $457 \mathrm{~nm}$ also excites the hemes and the corresponding TA reports on the consequences of both processes. We extracted the TA associated with Scheme 1, arising solely from excitation of the $\mathrm{Ru}(\mathrm{II})$-dye, through the following process described fully in the Supporting Information. The TA arising solely from electronically excited His/His ligated heme, e.g. Figure S4, was defined by pulsed irradiation of S77C STC. The TA of S77C STC, after appropriate scaling to account for the concentration of excited heme in each sample, was then subtracted from the TA of $\mathrm{Ru}_{77}$ :STC to reveal the features associated with Scheme 1. The resulting differential spectra are presented in Figure 3. We note that the photochemistry of $\mathrm{Ru}_{77}$ :STC extends to approximately $60 \mathrm{~ns}$ while that of S77C STC was complete within $50 \mathrm{ps,} \mathrm{and} \mathrm{that}$ data points between 438 and $465 \mathrm{~nm}$ are excluded due to scattering of the pump pulse into the probe path.

TA Assignment and Analysis for $\mathrm{Ru}_{77}: \mathrm{STC}$. In the differential spectra of Figure 3, chromophores with transiently depleted populations give negative features while those with transiently increased populations give positive features. The

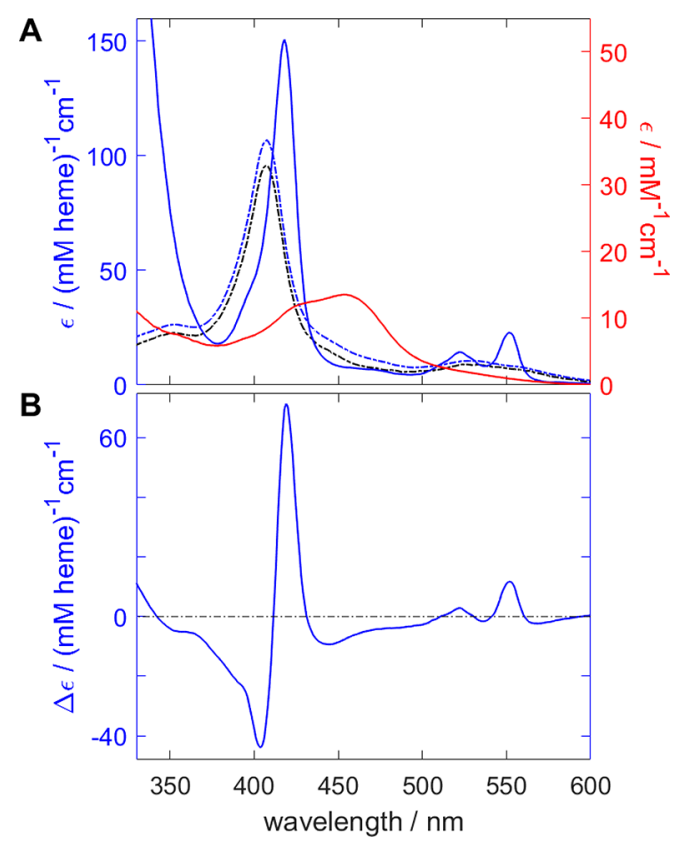

Figure 2. Ground state absorbance of $\mathrm{Ru}_{77}: \mathrm{STC}$ and $\left[\mathrm{Ru}(\mathrm{bpy})_{3}\right]^{2+}$. (A) Electronic absorbance of $\mathrm{Ru}_{77}$ :STC in the oxidized, all Fe(III) state (blue broken line) and the dithionite reduced, all $\mathrm{Fe}$ (II) state (blue continuous line), together with that of oxidized S77C STC (black line) and $\left[\mathrm{Ru}(\mathrm{bpy})_{3}\right]^{2+}$ (red). Extinction coefficients for STC and $\mathrm{Ru}: \mathrm{STC}$ are derived from those reported by Leys et al. ${ }^{16}$ assuming equal contribution from each heme. (B) Reduced minus oxidized difference spectrum for $\mathrm{Ru}_{77}: \mathrm{STC}$.

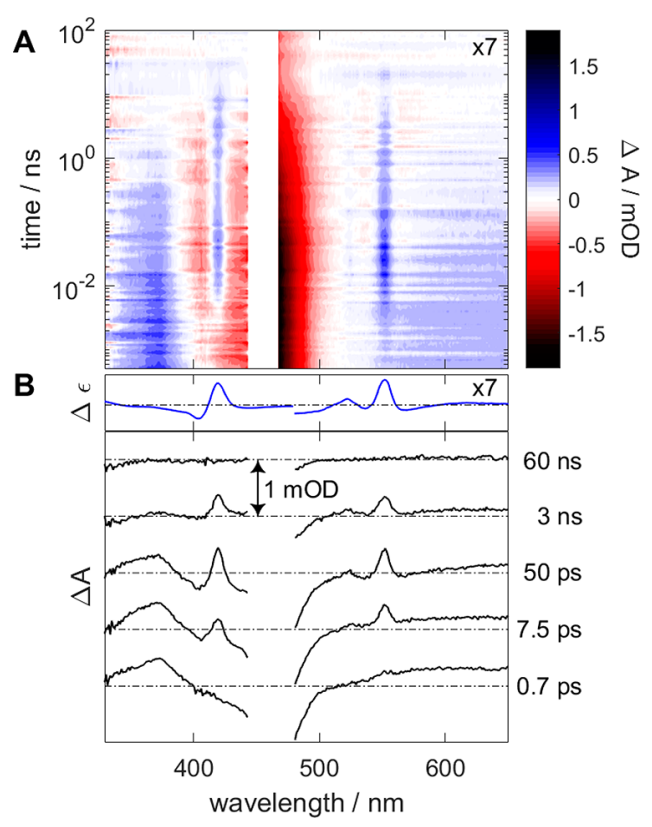

Figure 3. Transient absorbance of $\mathrm{Ru}_{77}$ :STC. (A) Differential TA; blue $=$ positive features, red $=$ negative features. (B) TA spectra (black lines) for the indicated times after irradiation together with the difference spectrum (blue line) for chemically reduced minus oxidized $\mathrm{Ru}_{77}$ :STC with extinction coefficients omitted for clarity. Pulsed irradiation was at $457 \mathrm{~nm}$ and contributions from electronically excited hemes are removed, see text for details. Samples contained $\mathrm{Ru}_{77}$ :STC $(22 \mu \mathrm{M}$ for measurement $<440 \mathrm{~nm}, 160 \mu \mathrm{M}$ for measurements $>480 \mathrm{~nm}$ ) in anaerobic $20 \mathrm{mM}$ Tris-HCl, $0.1 \mathrm{M}$ $\mathrm{NaCl}, \mathrm{pH} 8.5$. 
broad trough between $\sim 400$ and $500 \mathrm{~nm}$ describes depletion of the ground state dye concentration. At the shortest times, e.g. $0.7 \mathrm{ps}$, the positive features arise from absorbance by the dye triplet excited state, formally $\left[\mathrm{Ru}(\mathrm{III})(\mathrm{bpy})_{2}\left(\mathrm{bpy}^{-}\right)\right]_{\text {STC77 }}^{2+}$. By comparison to the properties ${ }^{43-46}$ of analogous complexes, we attribute the peak at $369 \mathrm{~nm}$ to $\pi \rightarrow \pi^{*}$ transitions in the anionic bpy $^{-}$ligand and the broad positive feature above $\sim 520$ $\mathrm{nm}$ to the ligand-to-metal charge transfer (LMCT) band arising from neutral bpy-to- $\mathrm{Ru}(\mathrm{III})$ transitions. These assignments are supported by our TA, Figure 4 and Figure S3, of

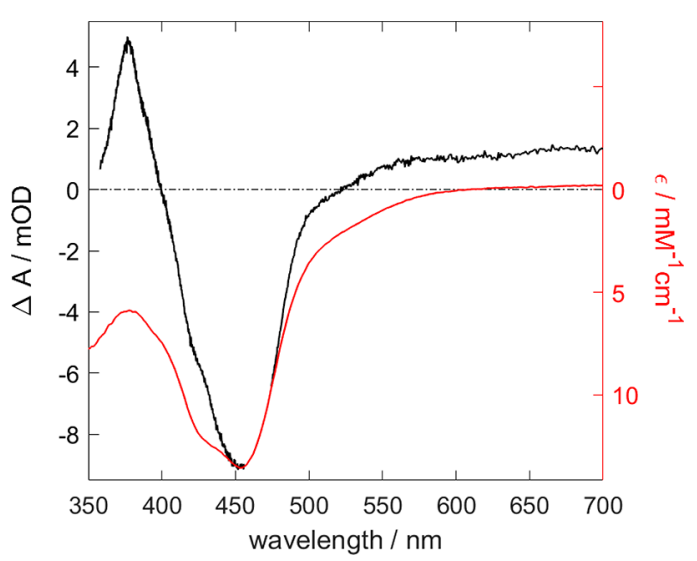

Figure 4. Spectral properties of ${ }^{3}\left[\mathrm{Ru}(\mathrm{bpy})_{3}\right]^{2+}$ (black) and absorbance of $\left[\mathrm{Ru}(\text { bpy })_{3}\right]^{2+}$ (red). Differential TA 10 ps after excitation of the $\left[\mathrm{Ru}(\mathrm{bpy})_{3}\right]^{2+}$ dye (black line). The $\left[\mathrm{Ru}(\mathrm{bpy})_{3}\right]^{2+}$ ground state absorbance (red line) is presented with an inverted $y$-axis to best illustrate how ground state depletion contributes to the differential TA presented here and in Figure 3.

respectively $\left[\mathrm{Ru}(\mathrm{bpy})_{3}\right]^{2+}$ and the dye attached ${ }^{9}$ to the protein bovine serum albumin that contains no cofactors. We find no spectral evidence for the immediate product of photoexcitation, the singlet excited state ${ }^{1} \mathrm{Ru}_{77}:$ STC, Scheme 1 , an observation in accord with the rapid intersystem crossing (ISC) reported ${ }^{47,48}$ for analogous systems.

Between $\sim 3$ ps and 20 ns the differential spectra of Figure 3 contain a narrow trough at $408 \mathrm{~nm}$ and peaks at 419, 522, and $552 \mathrm{~nm}$. The $\mathrm{Fe}(\mathrm{III})$ hemes in $\mathrm{Ru}_{77}$ :STC display a Soret maximum at $408 \mathrm{~nm}$ while the chemically reduced, tetra- $\mathrm{Fe}$ (II) forms display maxima at 419,522 , and $552 \mathrm{~nm}$, Figure $2 \mathrm{~A}$ blue continuous line. Thus, the differential spectra reveal transient conversion of $\mathrm{Fe}(\mathrm{III})$ to $\mathrm{Fe}(\mathrm{II})$ heme and consequently formation of the $\mathrm{Ru}_{77}^{+}: \mathrm{STC}^{-}$charge separated state. Direct spectral evidence for the oxidized dye, formally [Ru(III)(bpy $\left.)_{3}\right]_{\text {STC77 }}^{3+}$, is hard to discern. In analogous complexes the LMCT band ${ }^{45}$ arising from the oxidized $\mathrm{Ru}$-dye is a broad feature above $\sim 520 \mathrm{~nm}$ very similar in shape and intensity to that originating from the triplet excited state.

Having assigned all features in the differential spectra of Figure 3 to species in Scheme 1, the most prominent feature(s) were used to define the transient populations of these species. Due to overlapping contributions from multiple chromophores this was facilitated by line shape fitting across an appropriate wavelength range as exemplified in Figure 5 and fully described in the Supporting Information. For example, the absorbance due to $\mathrm{Ru}_{77}^{+}: \mathrm{STC}^{-}$was defined at $419 \mathrm{~nm}$, after removing contributions from the $\mathrm{Ru}_{77}$ :STC ground state bleach and bpy ${ }^{-} \pi-\pi^{*}$ absorption of ${ }^{3} \mathrm{Ru}_{77}:$ STC, and independently at $552 \mathrm{~nm}$, after removing contributions from the dye LMCT bands of ${ }^{3} \mathrm{Ru}_{77}: \mathrm{STC}$ and $\mathrm{Ru}_{77}^{+}: \mathrm{STC}^{-}$. The results of both analyses are in good agreement, e.g., Figure S5B. The $\mathrm{Ru}_{77}^{+}: \mathrm{STC}^{-}$concentration was calculated from its absorbance at $419 \mathrm{~nm}$ using the differential extinction coefficient of 71427 $\mathrm{M}^{-1} \mathrm{~cm}^{-1}$ obtained assuming each heme contributes equally to the absorbance of tetra-Fe(III) and tetra-Fe(II) STC, Figure 2B.

The transient concentration of depleted $\mathrm{Ru}_{77}$ :STC was defined by the dye ground state bleach using an extinction coefficient ${ }^{38}$ of $14.6 \mathrm{mM}^{-1} \mathrm{~cm}^{-1}$ for the dye MLCT band at $453 \mathrm{~nm}$. The amplitude of the ground state bleach at this wavelength was derived by modeling with a Gaussian line shape, e.g., Figure 5. The transient concentration of ${ }^{3} \mathrm{Ru}_{77}$ :STC was obtained from the differential absorbance at $369 \mathrm{~nm}$ after accounting for contributions from the ground state bleach. For this wavelength, an extinction coefficient of $13.6 \mathrm{mM}^{-1} \mathrm{~cm}^{-1}$ for ${ }^{3} \mathrm{Ru}_{77}$ :STC was derived from the TA of $\left[\mathrm{Ru}(\mathrm{bpy})_{3}\right]^{2+}$, Figure 4 . This is possible because after vibrational cooling, the dye ground state bleach describes a concentration equal to that of triplet state, and the latter species has negligible absorbance between 430 and $500 \mathrm{~nm}$. ${ }^{45}$

Figure 6 presents the outcomes of the above analysis, specifically, the transient populations of ${ }^{3} \mathrm{Ru}_{77}: \mathrm{STC}$ and $\mathrm{Ru}_{77}^{+}: \mathrm{STC}^{-}$together with recovery of the $\mathrm{Ru}_{77}: \mathrm{STC}$ population. No additional species are needed to describe the

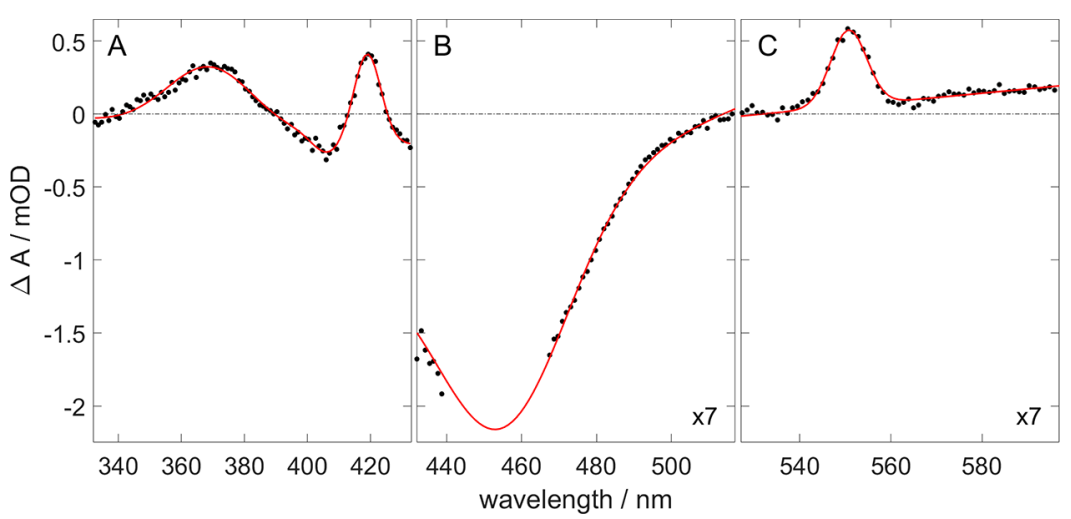

Figure 5. TA of $\mathrm{Ru}_{77}: \mathrm{STC}$ at $30 \mathrm{ps}$ after $457 \mathrm{~nm}$ excitation. Data (black circles) and fits (red lines) for spectral windows covering (A) $\pi-\pi^{*}$ absorption of the anionic bpy ${ }^{-}$ligand in ${ }^{3} \mathrm{Ru}_{77}$ :STC and the heme Soret band, (B) ground-state bleach of the Ru-dye, and, (C) heme $\alpha$-band (552 $\mathrm{nm}$ maximum) and the Ru-dye LMCT band of ${ }^{3} \mathrm{Ru}_{77}: \mathrm{STC}$ and $\mathrm{Ru}_{77}^{+}: \mathrm{STC}^{-}$. 


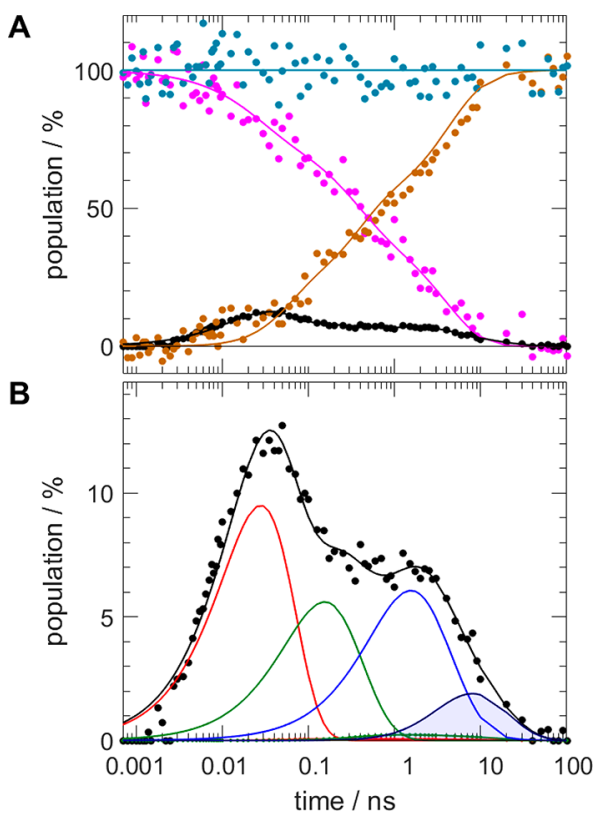

Figure 6. Progress of the $\mathrm{Ru}_{77}$ :STC photocycle. (A) Evolution of the experimentally defined concentrations (circles) of ${ }^{3} \mathrm{Ru}_{77}: \mathrm{STC}$ (pink) and $\mathrm{Ru}_{77}^{+}: \mathrm{STC}^{-}$(black) together with recovery of $\mathrm{Ru}_{77}: \mathrm{STC}$ (brown) and the total concentration of these species (dark cyan). Fit to Scheme 3 (lines) with the parameters of Table 1 (fit). The population of ${ }^{3} \mathrm{Ru}_{77}$ : $\mathrm{STC}$ at 0.7 ps was defined as $100 \%$. (B) Expanded view of the population of $\mathrm{Ru}_{77}^{+}: \mathrm{STC}^{-}$shown in A) from experiment (black circles) and fit to Scheme 3 (black line) with the Table 1 parameters (fit). Contributions to the fit from $\mathrm{CS}^{\mathrm{IV}}$ (lines, no fill) and $\mathrm{CS}^{\mathrm{III}}$ (lines, shaded fill) are shown for conformers $a$ (red), $b$ (green), and $c$ (blue). Note, contributions to $\mathrm{CS}^{\mathrm{III}}$ from conformers $a$ and $b$ are very small and hardly visible.

photocycle as the excited population is accounted for throughout.

Electron Transfer Dynamics in $\mathrm{Ru}_{77}: \mathrm{STC}$. We have previously shown ${ }^{9}$ that the photoluminescence of the Ru-dye, Scheme 1, pathway 3 , is very significantly $(>98 \%)$ quenched when attached to S77C STC. Furthermore, in $\mathrm{Ru}_{77}$ :STC the charge separation, Scheme 1, pathway 1 , and charge recombination, Scheme 1 , pathway 2 , are strongly exergonic and hence irreversible processes. As a consequence, decay of the ${ }^{3} \mathrm{Ru}_{77}$ :STC population is expected to be monoexponential. The TA reveals this is not the case, Figure $6 \mathrm{~A}$ pink circles. To account for the observed behavior several modifications and extensions of the reaction scheme were explored. In all cases the behavior was attributed to intramolecular electron transfer within $\mathrm{Ru}_{77}$ :STC monomers. There is good agreement between the dynamics of the charge separated states at 22 and $160 \mu \mathrm{M}$ protein, Figure S5A, and analytical ultracentrifugation, Figure S2, defined the solution mass of $\mathrm{Ru}_{77}$ :STC at $22 \mu \mathrm{M}$ as $\sim 15400 \mathrm{Da}$, a value close that of $14056 \mathrm{Da}$ measured for the monomer by LC-MS.

As described fully in the Methods and Supporting Information sections, fits to different reaction schemes were obtained by solving a chemical Master equation assuming that all protein is initially ${ }^{3} \mathrm{Ru}_{77}: \mathrm{STC}$. The only scheme to produce a reasonable fit to the ${ }^{3} \mathrm{Ru}_{77}$ : $\mathrm{STC}$ decay included several kinetically distinct forms of the $\mathrm{Ru}$-dye labeled protein. This is indicated in Scheme 2 where $x$ indicates kinetically distinct populations $a, b$, etc. and $y$ indicates the Ru-dye attachment site.
Given the ultrafast time scale of charge separation we assign the kinetically distinct populations to different conformers of the Ru-labeled protein. This assumption is supported by MD simulations, described below, where different conformers do not interconvert on the time scale of charge separation and recombination. The multiple conformer model was then expanded to include reversible heme-heme electron transfer by replacing $\mathrm{Ru}_{77}^{+}: \mathrm{STC}^{-}$of Scheme 2 with $\mathrm{CS}_{x}^{\mathrm{IV}}$ and $\mathrm{CS}_{x}^{\mathrm{III}}$ as illustrated in Scheme 3. In Scheme 3 it is assumed that the immediate product of charge separation contains reduced Heme IV, the site closest to the Ru-dye. This assumption is supported by calculations, as described in the following section. Electron migration along the heme chain is then included as the $\mathrm{CS}_{x}^{\mathrm{NI}} \leftrightarrow \mathrm{CS}_{x}^{\mathrm{III}}$ interconversion where the electron resides on Heme III in CS ${ }^{\mathrm{III}}$ and $k_{\mathrm{III}, \mathrm{IV}}$ describes the rate constant for Heme IV $\rightarrow$ Heme III electron transfer. To keep the required fit parameters to a minimum, we assume that $k_{\mathrm{II}, \mathrm{IV}}$ is the same for all conformers $x$. As we will see, Heme IV $\rightarrow$ Heme III electron transfer predominantly occurs in a single conformer that exhibits the slowest recombination kinetics, hence justifying the choice of a single rate constant $k_{\mathrm{III}, \mathrm{IV}}$.

Scheme 3 produces an excellent description, evidenced by the lines in Figure 6, of the measured behavior when three conformers, $a$ to $c$, participate with the individual contributions and rate constants presented in Table 1 fit. Without Heme IV

Table 1. Electron Transfer Rate Constants ${ }^{b}$ for the $\mathrm{Ru}_{77}:$ STC Photocycle ${ }^{a}$

\begin{tabular}{lllll} 
& & \multicolumn{3}{c}{ conformer } \\
\cline { 3 - 5 } & & \multicolumn{1}{c}{$a$} & \multicolumn{1}{c}{$b$} & \multicolumn{1}{c}{$c$} \\
contribution (\%) & fit & 22 & 33 & 45 \\
$k_{\mathrm{CS}}\left(/ 10^{6} \mathrm{~s}^{-1}\right)$ & fit & 41700 & 3300 & 261 \\
& $\mathrm{MD} / \mathrm{DFT}^{d}$ & 333000 & 66700 & 256 \\
$k_{\mathrm{CR}}\left(/ 10^{6} \mathrm{~s}^{-1}\right)$ & $\mathrm{fit}$ & 30300 & 11400 & 1230 \\
& $\mathrm{MD} / \mathrm{DFT}^{d}$ & 7190 & 6710 & 588 \\
$k_{\mathrm{III}, \mathrm{IV}}\left(/ 10^{6} \mathrm{~s}^{-1}\right)$ & $\mathrm{fit}^{c}$ & 87 & 87 & 87 \\
& $\mathrm{MD} / \mathrm{DFT}^{c, e}$ & 17 & 17 & 17
\end{tabular}

${ }^{a}$ Values are derived from fit to the observed transients and from MD/ DFT calculation as described in the text and the Supporting Information. ${ }^{b} k_{\mathrm{CS}}, k_{\mathrm{CR}}$, and $k_{\mathrm{IIJIV}}$ are as defined in Scheme 3 , and the parameters used for $\mathrm{MD} / \mathrm{DFT}$ calculations are summarized in Tables S5 and S6. ${ }^{c}$ Assumed to be the same for all conformers. ${ }^{d}$ Values for $a$ averaged over two conformers (1 and 2) with shortest bpy-to-heme edge distances, see text for details. ${ }^{e}$ From Jiang et al. ${ }^{18}$ Table S4, state "(O,d)".

$\leftrightarrow$ Heme III electron transfer, the fit of the $\mathrm{Ru}_{77}^{+}: \mathrm{STC}^{-}$ population predicted by Scheme 2 at long-times $(10-50 \mathrm{~ns})$ is worse (see Figure S6B, $R^{2}=0.966$ versus 0.971 without and with interheme electron transfer respectively). We also note that the fit presented in Figure 6 with parameters in Table 1 includes the minimum number of kinetically distinct conformers needed to explain the TA data, and gives the best fit to the most certain experimentally defined population, that of $\mathrm{Ru}_{77}^{+}: \mathrm{STC}^{-}$, due to highest signal-to-noise. Models with more than three reactive conformers do not reproduce the data significantly better. There was no advantage to including electron transfer further along the STC heme chain, e.g., from Heme III $\rightarrow$ Heme II, in the kinetic model. However, we do not rule out such electron transfer and return to consider this possibility further in the Discussion section. 
From the description of the $\mathrm{Ru}_{77}$ :STC photochemistry presented in Figure 6 it is apparent that, in addition to Heme $\mathrm{IV} \rightarrow$ Heme III electron transfer with $k_{\mathrm{IIIIV}}=87 \times 10^{6} \mathrm{~s}^{-1}$, contributions from multiple conformers are required to account for the complete photocycle that extends from 0.2 pico- to 1 milli-second after excitation of the photosensitizer. For conformer $a$ where charge separation and recombination are fastest and have rate constants much greater than $k_{\mathrm{IIIIV}}$, the model predicts $\mathrm{Ru}_{77}^{+}: \mathrm{STC}^{-}$existing only as $\mathrm{CS}^{\mathrm{IV}}$, Figure $6 \mathrm{~B}$ red line. By contrast, in conformer $c$ where charge separation and recombination are slowest, Heme IV $\rightarrow$ Heme III electron transfer is competitive with charge recombination and a significant amount of $\mathrm{CS}^{\mathrm{III}}$ is predicted in addition to $\mathrm{CS}^{\mathrm{IV}}$, Figure $6 \mathrm{~B}$ blue shaded and blue open, respectively. Further consideration of the Heme IV $\leftrightarrow$ Heme III electron transfer rate constants and their implications for the electron transfer mechanism is presented in the Discussion that concludes this paper.

Atomistic Description of $\mathrm{Ru}_{77}$ :STC Photochemistry. As noted above, a key feature of the kinetic model describing the $\mathrm{Ru}_{77}$ :STC photocycle is the presence of three $\mathrm{Ru}$-conformers with different rate constants for electron exchange between the $\mathrm{Ru}$-dye and Heme IV. We assessed the validity of this model through molecular docking and MD simulation to consider the nature of the predicted conformers. A structural model of $\mathrm{Ru}_{77}$ :STC was obtained by docking $\left[\mathrm{Ru}(\mathrm{II})(\text { bpy })_{2}\left(4-\mathrm{CH}_{2}-4^{\prime}-\right.\right.$ methylbipyridine) $]^{2+}$ to the crystal structure ${ }^{16}$ of STC (pdb identifier: $1 \mathrm{M} 1 \mathrm{Q}$ ) with serine 77 modified to cysteine (see the Methods and Supporting Information sections for details). Of the 100000 docking structures generated four were particularly low in energy and selected as initial structures for MD runs (total length $400 \mathrm{~ns}$ ). Analysis of the MD trajectories shows that the label adopts four distinct conformations, see Figure 7A where, for clarity, only three are shown. These conformations are stable on the nanosecond time scale and populate distinct low-energy basins characterized by dihedral angles $\tau_{2}$ and $\tau_{3}$, Figure $7 \mathrm{~B}$. In two conformers, $\mathbf{1}$ and 2 , a bpy ligand of the $\mathrm{Ru}-$ dye approaches the Heme IV ring very closely, bpy-to-heme edge-edge distance $=5.2 \AA$ (thermal average), whereas in the other two conformers 3 and 4 the distances are larger, 6.1 and $8.5 \AA$, Figure $7 \mathrm{C}$. The corresponding distances to the nextnearest heme III are larger, by $3 \AA$ or more, suggesting that simultaneous electron injection into heme III is significantly slower and can be neglected to a good approximation.

For all four conformers we computed parameters relevant to charge separation and recombination of Scheme 3 using MD simulation and DFT electronic structure calculations as described in the Methods and Supporting Information sections. The relevant frontier orbitals for charge separation from ${ }^{3} \mathrm{Ru}_{77}$ :STC to Heme IV are shown in Figure $7 \mathrm{D}$ and the ones for charge recombination from $\mathrm{Ru}_{77}^{+}: \mathrm{STC}^{-}$in Figure $\mathrm{S} 12$. We find that electronic coupling between these states for charge separation is lower by approximately 1 order of magnitude for the conformer with the largest bpy-to-heme edge distance (4, Figure 7E blue) compared to the conformers with the shorter distances ( 1 and 2, Figure 7E black and red). A similar trend is obtained for the coupling between frontier orbitals for charge recombination. By contrast, the reorganization free energy, suitably corrected ${ }^{17}$ for nonergodic effects on the present ultrafast time scale, is higher by about $0.2 \mathrm{eV}$ for 4 than for 1 and 2 . Using these electron transfer parameters three distinct sets of rate constants are calculated, all spanning the ps-ns regime (summarized in Table 1). One set arises from
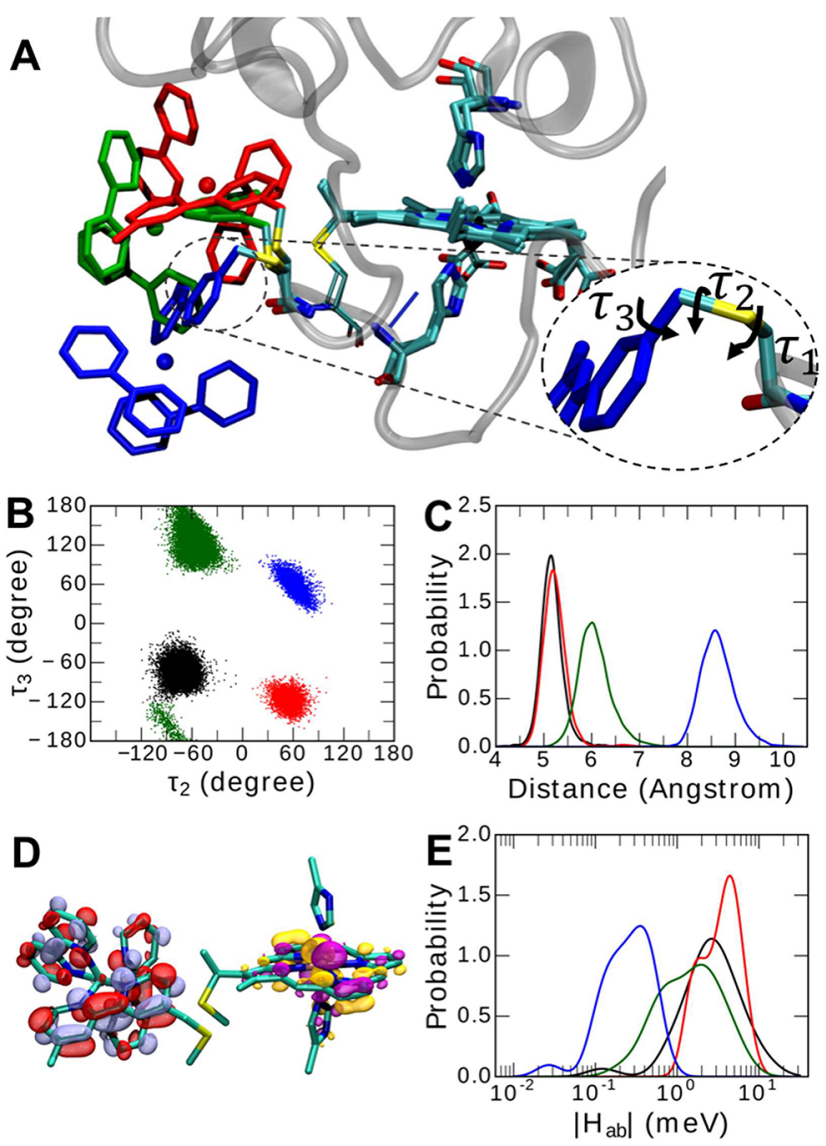

Figure 7. Molecular models of the reactive conformers of $\mathrm{Ru}_{77}: \mathrm{STC}$. (A) Three of the four low-energy conformers obtained from molecular docking. The three structures are aligned with respect to the $\mathrm{Fe}$ atom of Heme IV, shown in stick representation ( $\mathrm{C}$ cyan, $\mathrm{N}$ blue, $\mathrm{O}$ red and $\mathrm{S}$ yellow). The $\left[\mathrm{Ru}(\mathrm{bpy})_{3}\right]^{2+}$ label of conformers $\mathbf{1}, \mathbf{3}$, and $\mathbf{4}$ are shown in red, green, and blue, respectively, and the protein backbone is depicted in gray. The Ru-label of the lowest energy conformer, 2, adopts a similar conformation as $\mathbf{1}$ but is not shown to enhance clarity of the illustration. (B) Scatter of dihedral angles $\tau_{2}$ and $\tau_{3}$ (defined in (A) inset), as obtained from MD simulation. (C) Probability distributions of the smallest distance between the $\mathrm{C}$ atoms of the bpy ligands and the Heme IV edge. (D) Pair of redox active frontier orbitals contributing to electronic coupling for charge separation. (E) Probability distribution of electronic coupling for ${ }^{3} \mathrm{Ru}_{77}: \mathrm{STC} \rightarrow \mathrm{Ru}_{77}^{+}: \mathrm{STC}^{-}\left(\mathrm{CS}^{\mathrm{IV}}\right)$ charge separation as obtained from $\mathrm{MD}$ simulations and DFT calculations on the conformers, see main text and the Supporting Information for details. The color code in (B), (C), and (E) is the same as in (A) with the data for conformer 2 in black. In Table $1, \mathbf{1}$ and $\mathbf{2}$ are assigned to conformer $a$, and conformers 3 and 4 to $b$ and $c$, respectively.

the two conformers with the smallest distances, $\mathbf{1}$ and $\mathbf{2}$, and one set each from 3 and 4 . These sets are assigned to the kinetically distinct conformers $a(\mathbf{1}+2), b(3)$, and $c$ (4) proposed in our model of the TA data in order of decreasing charge separation rate constants, see Table 1 . The sets of charge separation and charge recombination rate constants, obtained here from DFT and MD calculations without empirical adjustments, are in good agreement with predictions from empirical tunneling models ${ }^{49,50}$ as described in Table S6. We note that additional reactive conformers may exist in addition to the ones we have found, but we would expect their electron transfer kinetics to be similar to those of either $a, b$, or c. 
Comparison of measured and calculated rates for charge separation and recombination, Table 1 , shows they are in reasonable agreement, typically within an order of magnitude, and gives confidence in our kinetic model for the photochemistry of $\mathrm{Ru}_{77}$ :STC, Scheme 3. A better agreement between computation and experiment can hardly be expected given that model structures of the Ru-labeled STC are used for the calculations and that charge separation and charge recombination rates are very sensitive to small changes in donor/ acceptor distance and orientation. We note that the high rate constants for charge separation are consistent with a quantum yield for charge separation of $\sim 1$. The rates of charge separation and recombination are also seen to be higher than for many other studies of light-driven protein electron transfer, where the relevant redox centers are separated by larger distances and electron transfer is slower than for $\mathrm{Ru}_{77}$ :STC. ${ }^{22,24-27}$ This can in part explain why to date we have been unable to employ flash-quench approaches effectively with this system.

Photochemistry and Electron Transfer Dynamics of $\mathrm{Ru}_{23}:$ STC and $\mathrm{Ru}_{10}: \mathrm{STC}$. In view of the conclusions reached from experiment and calculation of the properties of $\mathrm{Ru}_{77}$ :STC, a similar approach was used to investigate the consequences of light-driven electron transfer into STC Heme I, at the opposite end of the heme chain to Heme IV, Figure 1. $\mathrm{Ru}_{10}$ :STC and $\mathrm{Ru}_{23}$ :STC were used for these studies. The $\mathrm{Ru}(\mathrm{II})$-dye photoluminescence is very significantly quenched ${ }^{9}$ (>98\%) when attached to both proteins which are monomeric in the conditions of the corresponding experiments. The dynamics of the corresponding charge separated states are in good agreement at $\sim 20$ and $160 \mu \mathrm{M}$ protein and analytical gel filtration produced elution profiles indistinguishable from that of monomeric $\mathrm{Ru}_{77}$ :STC.

The transient populations of $\mathrm{Ru}_{23}$ :STC after excitation into the MLCT-band of the $\mathrm{Ru}(\mathrm{II})$-dye are presented in Figure 8 circles. Noting that decay of ${ }^{3} \mathrm{Ru}_{23}$ :STC is multiexponential, multiple possible reaction schemes were again explored to describe the intramolecular electron transfer dynamics. Scheme $4(y=23)$ describes three reactive conformers $(a-c)$ and electron migration along the heme chain, now as $\mathrm{CS}_{x}{ }^{\mathrm{I}} \leftrightarrow \mathrm{CS}_{x}{ }_{x}$ interconversion in the charge separated state. This Scheme with the parameters of Table 2 (fit) includes the minimum number of kinetically distinct conformers needed to explain the TA data, Figure 8 lines, and gives the best fit to the most certain experimentally defined population, that of $\mathrm{Ru}_{23}^{+}: \mathrm{STC}^{-}$. The slower reacting conformer $(c)$ displays significant Heme I $\rightarrow$ Heme II electron transfer with a rate constant $125 \times 10^{6}$ $\mathrm{s}^{-1}$. Without interheme electron transfer the fit of the $\mathrm{Ru}_{23}^{+}$:STC ${ }^{-}$population, Scheme 2, at long-times (3-500 ns) is worse (see Figure $S 7, R^{2}=0.928$ versus 0.972 without and with interheme electron transfer respectively). Models with more than three reactive conformers do not reproduce the data significantly better and there was no advantage to including Heme II $\rightarrow$ Heme III electron transfer in the model.

For $\mathrm{Ru}_{10}: \mathrm{STC}$, excitation into the dye MLCT-band again resolved spectral features characteristic of the species in Scheme 1 but two models produced equally good fits to the transient populations; Scheme 4 with three reacting conformers and heme-heme electron transfer and Scheme 2 with four reacting conformers but no heme-to-heme electron transfer. The corresponding fits and parameters are summarized in Figure S8 and Table S4, respectively. With four reacting conformers the variations in $k_{\mathrm{CS}} / k_{\mathrm{CR}}$ are $>10^{3}$ and, while it is

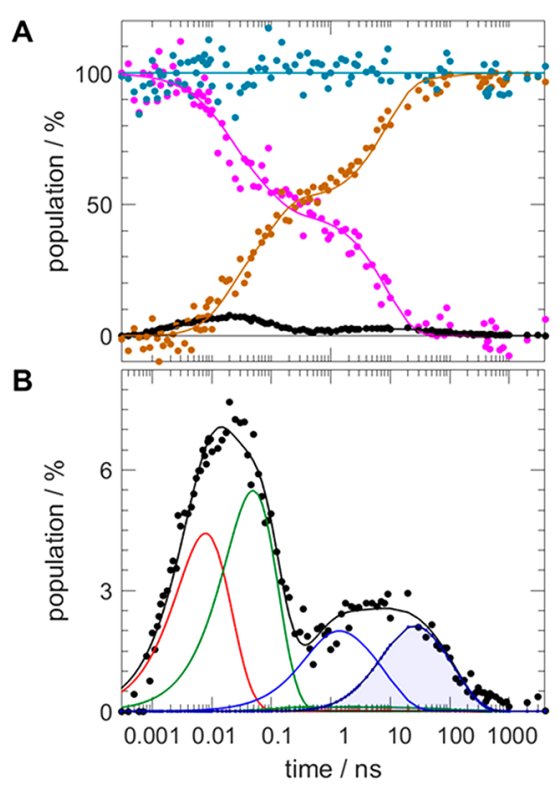

Figure 8. Progress of the $\mathrm{Ru}_{23}$ : $\mathrm{STC}$ photocycle. (A) Evolution of the experimentally defined concentrations (circles) of ${ }^{3} \mathrm{Ru}_{23}: \mathrm{STC}$ (pink) and $\mathrm{Ru}_{23}^{+}: \mathrm{STC}^{-}$(black) together with recovery of $\mathrm{Ru}_{23}: \mathrm{STC}$ (brown) and the total concentration of these species (dark cyan). Fit to Scheme 4 (lines) with the parameters of Table 2 (fit). The population of ${ }^{3} \mathrm{Ru}_{23}$ :STC at 0.7 ps was defined as $100 \%$. (B) Expanded view of the population of $\mathrm{Ru}_{23}^{+}: \mathrm{STC}^{-}$shown in A) from experiment (black circles) and fit to Scheme 4 (black line) with the Table 2 parameters (fit). Contributions to the fit from $\mathrm{CS}^{\mathrm{I}}$ (lines, no fill) and $\mathrm{CS}^{\mathrm{II}}$ (lines, shaded fill) are shown for conformers $a$ (red), $b$ (green), and $c$ (blue). Note, contributions to $\mathrm{CS}^{\mathrm{II}}$ from conformers $a$ and $b$ are very small and hardly visible.

Table 2. Electron Transfer Rate Constants ${ }^{b}$ for the $\mathrm{Ru}_{23}:$ STC Photocycle ${ }^{a}$

\begin{tabular}{lllll} 
& & \multicolumn{3}{c}{ conformer } \\
\cline { 3 - 5 } & & \multicolumn{1}{c}{$a$} & \multicolumn{1}{c}{$b$} & \multicolumn{1}{c}{$c$} \\
contribution (\%) & fit & 27 & 26 & 47 \\
$k_{\mathrm{CS}}\left(/ 10^{6} \mathrm{~s}^{-1}\right)$ & fit & 62500 & 11900 & 113 \\
$k_{\mathrm{CR}}\left(/ 10^{6} \mathrm{~s}^{-1}\right)$ & fit & 250000 & 31200 & 2170 \\
$k_{\mathrm{II}, \mathrm{I}}\left(/ 10^{6} \mathrm{~s}^{-1}\right)$ & fit $^{c}$ & 125 & 125 & 125 \\
& $\mathrm{MD}^{c} \mathrm{DFT}^{c, d}$ & 8.7 & 8.7 & 8.7
\end{tabular}

${ }^{a}$ Values are derived from fit to the observed transients and from MD/ DFT calculation. ${ }^{b} k_{\mathrm{CS}}, k_{\mathrm{CR}}$ and $k_{\mathrm{III}}$ are as defined in Scheme 4 . ${ }^{c}$ Assumed to be the same for all conformers. ${ }^{d}$ From Jiang et al. ${ }^{18}$ Table S4, state " $(\mathrm{O}, \mathrm{d})$ ".

difficult to place an upper limit on this ratio, we consider values exceeding $10^{2}$ as unlikely. With three reactive conformers and heme-to-heme electron transfer in the slowest, all conformers have $k_{\mathrm{CS}} / k_{\mathrm{CR}}<11$. For this model the predicted Heme I $\rightarrow$ Heme II electron transfer rate constant of $143 \times 10^{6} \mathrm{~s}^{-1}$ is very similar to the value of $125 \times 10^{6} \mathrm{~s}^{-1}$ predicted from modeling the TA of $\mathrm{Ru}_{23}: \mathrm{STC}$.

\section{DISCUSSION}

Ultrafast TA has allowed us to measure with high temporal resolution and signal-to-noise the visible-light driven electron transfer dynamics in a multiheme cytochrome photosensitized by site-specific labeling with a $\mathrm{Ru}(\mathrm{II})(\mathrm{bpy})_{3}$ dye. For all proteins, the quantum yields for charge separation were high $(\sim 1)$ and the photochemistry well-described by kinetic 
models, supported by MD simulation and DFT calculation that include heme-heme electron transfer in competition with charge recombination. Our results have two important implications. First, they demonstrate that TA of Ru-labeled multiheme cytochromes provides a promising platform for determination of heme-to-heme electron transfer rates. These values are difficult to access experimentally due to the identical chemical nature of the heme groups, yet they are of major interest as they define the upper limit for electron flow in biological extracellular respiration ${ }^{11}$ and possibly in multiheme cytochrome-based bionanoelectronic junctions ${ }^{21,51,52}$ at humid/wet conditions. Second, as multiheme cytochromes have an ability to accumulate photoenergized electrons in the presence as sacrificial electron donors, ${ }^{9}$ the results provide a framework for rational development of photosensitized multiheme cytochromes to assist the coupling of one-electron photochemistry and multielectron chemical transformations for visible-light driven redox catalysis.

The heme-heme electron transfer rate constants defined here by TA for Ru-labeled STC and summarized in Figure 9

$$
I \underset{8.7(0.6)}{\stackrel{125(8.7)}{\rightleftarrows}} I I \underset{(74)}{\stackrel{(166)}{\rightleftarrows}} I I I \underset{87(17)}{\stackrel{114(13)}{\rightleftarrows}} I V
$$

Figure 9. STC heme-heme electron transfer rate constants. Values (in units of $10^{6} \mathrm{~s}^{-1}$ ) measured by TA in this work (blue) and calculated previously ${ }^{18}$ for the $1 \mathrm{e}^{-}$reduced protein (black).

(blue) are in line with the predictions ${ }^{53}$ from NMR studies of intramolecular electron exchange at rates $>10^{4} \mathrm{~s}^{-1}$, and are consistent with both stopped-flow kinetic analysis ${ }^{54}$ of STC reacting with nonphysiological redox partners, and MD simulations ${ }^{55}$ considering electron exchange between STC and the surface of hematite $\left(\alpha-\mathrm{Fe}_{2} \mathrm{O}_{3}\right)$. Also presented in Figure 9 (black) are the rate constants for heme-to-heme electron transfer predicted previously ${ }^{18}$ for native (i.e., unlabeled) STC using similar DFT and MD methodology as in the present study. We find that the computed rate constants are about 1 order of magnitude smaller than the experimental values, a factor of 7 for Heme IV $\rightarrow$ Heme III and a factor of 14 for Heme I $\rightarrow$ Heme II electron transfer. A possible reason for the greater discrepancy for the latter is that the reorganization free energy, $1.08 \mathrm{eV}$, might be overestimated in the calculations. For comparison, the predicted value ${ }^{18}$ for Heme IV $\rightarrow$ Heme III electron transfer is $0.88 \mathrm{eV}$. The error of these estimates due to inaccuracies of the protein and water force field is typically in the order of $0.1 \mathrm{eV}^{17}$ If the reorganization free energy for Heme I $\rightarrow$ Heme II electron transfer is lowered by $0.1 \mathrm{eV}$, to $0.98 \mathrm{eV}$, the deviation with respect to experiment decreases from a factor of 14 to 5 . An additional source of the discrepancy could be the presence of the Ru-label in the experimental measurements, which could give rise to a slight reduction in the reorganization free energy for the adjacent Heme IV $\rightarrow$ Heme III and Heme I $\rightarrow$ Heme II electron transfer. The terminal hemes, in particular Heme I, have a very high solvent accessible surface area in unlabeled STC and the attachment of the bulky and hydrophobic Rulabel in their vicinity will lower solvent access to the terminal hemes and therefore, most likely, lower reorganization free energy and increase the electron transfer rate. We do not think this effect is very large but possibly large enough to explain at least part of the remaining difference between computed and experimental rate constants.
Taking into account all of these uncertainties, the computed values give further support for the interpretation of the TA data in terms of light-initiated electron transfer across the $\mathrm{T}$ shaped Heme IV/III and Heme I/II pairs. As reported in our previous computational work, ${ }^{18}$ the mechanism of hemeheme electron transfer is electron hopping in the nonadiabatic regime assisted by weak mixing of the Fe-heme $d$ orbitals and sulfur $3 p$ orbitals. The sulfur orbitals are located in the cysteine linkages binding the hemes to the protein and inserting into the space between the hemes having a $\mathrm{T}$-shaped configuration. If the $\mathrm{Fe}-\mathrm{S}$ orbital mixing is excluded, the computed rate constants for Heme IV $\leftrightarrow$ Heme III and Heme I $\leftrightarrow$ Heme II electron transfer were predicted to be 18 -fold and 54-fold lower, respectively, and the deviation with the experimental rates reported herein would increase correspondingly. Hence, the experimental rates determined in this work support our hypothesis that orbital mixing accelerates electron transfer between these two T-shaped heme pairs. This effect is not restricted to STC but indeed has also been predicted for Tshaped and coplanar heme pairs in the deca-heme cytochromes MtrC and MtrF. ${ }^{21}$

In addition to their presence in STC, and the multiheme cytochromes $\mathrm{MtrC}^{56}$ and $\mathrm{MtrF}^{57}$ that participate in electron transfer across the outermembrane of $S$. oneidensis, T-shaped heme pairs are found ${ }^{7,8}$ alternating with stacked heme pairs in the electrically conductive extracellular G. sulfurreducens OmcS filaments that extend over distances $>10 \mu \mathrm{m}$. Our results suggest rate constants for electron transfer between these $\mathrm{T}$ shaped hemes can be accurately predicted using the mechanisms and approaches described above. For STC those methods predict rate constants for electron transfer between the stacked Heme II/III pair that are approximately an order of magnitude greater than for the T-shaped heme pairs. This may explain why there is no benefit to including electron migration further along the STC heme chain, e.g. Heme II $\rightarrow$ Heme III after injection into Heme I, and Heme III $\rightarrow$ Heme II after injection into Heme IV, in our kinetic models.

In closing we note that in a previous study ${ }^{23}$ by Kokhan and colleagues reported ultrafast TA of a triheme containing cytochrome, PpcA, photosensitized for light-driven electron transfer in the same way as the STC proteins described here. Charge separated states were generated from photoexcitation of the fully oxidized, and fully reduced, PpcA. Nevertheless the authors were unable to find evidence for heme-to-heme electron transfer. In view of the results presented here we suggest that this does not preclude light-driven heme-to-heme electron transfer in $\mathrm{Ru}: \mathrm{PpcA}$. Rather this process may have gone undetected due to contributions from a number of reactive conformers and/or the relative rates of electron transfer in the corresponding photocycles. As illustrated here the evidence for heme-to-heme electron transfer is compelling for $\mathrm{Ru}_{77}:$ STC and $\mathrm{Ru}_{23}$ :STC but less clear-cut for $\mathrm{Ru}_{10}$ :STC. Moving forward experiments exploring the opportunities to obtain direct evidence for heme-heme electron transfer through pump-probe spectroscopies of multiheme cytochromes containing spectroscopically distinct, e.g., His/Met coordinated or high-spin heme, at a defined location, are ongoing in our laboratories.

\section{ASSOCIATED CONTENT}

\section{S Supporting Information}

The Supporting Information is available free of charge on the ACS Publications website at DOI: 10.1021/jacs.9b06858. 
Full methods of protein preparation, data collection, analysis, fitting to kinetic models, molecular docking, MD simulations, calculation of electron transfer parameters and rate constants (PDF)

\section{AUTHOR INFORMATION}

\section{Corresponding Authors}

*s.meech@uea.ac.uk

*j.blumberger@ucl.ac.uk

*j.butt@uea.ac.uk

\section{ORCID}

Jessica H. van Wonderen: 0000-0003-0764-5453

Christopher R. Hall: 0000-0003-1267-1277

Xiuyun Jiang: 0000-0001-6884-411X

Ismael Heisler: 0000-0002-8581-4745

Stephen R. Meech: 0000-0001-5561-2782

Jochen Blumberger: 0000-0002-1546-6765

Julea N. Butt: 0000-0002-9624-5226

\section{Present Addresses}

${ }^{\nabla}$ ARC Centre of Excellence in Exciton Science, School of Chemistry, The University of Melbourne, Parkville, Victoria 3010, Australia.

\#Departamento de Física, Universidade Federal do Paraná, Caixa Postal 19044, 81531-990 Curitiba, Parana, Brazil.

^PASTEUR, Département de Chimie, École Normale Supérieure, PSL University, Sorbonne Université, CNRS, 75005 Paris, France.

\section{Author Contributions}

${ }^{\perp}$ J.H.v.W., C.R.H., X.J., and K.A. contributed jointly to this work.

\section{Notes}

The authors declare no competing financial interest.

\section{ACKNOWLEDGMENTS}

We are grateful to STFC for access to the ULTRA laser facility and the EPSRC UK National Mass Spectrometry Facility at Swansea University for characterisation of $\mathrm{Ru}(\mathrm{II})$ (4-bromomethyl-4'-methylbipyridine $)(\mathrm{bpy})_{2}\left(\mathrm{PF}_{6}\right)_{2}$. Funding was from the UK Engineering and Physical Sciences Research Council (EP/M001989/1, EP/M001946/1, and EP/N033647/1), UK Biotechnology and Biological Sciences Research Council (BB/ L022176/1, BB/K009885/1, BB/S02499/1, BB/R013578/1, and Doctoral Training Partnership Ph.D. studentship to S.E.H.P.). X.J. was supported by a Ph.D. studentship cosponsored by the Chinese Scholarship Council and University College London. JNB acknowledges a Royal Society Leverhulme Trust Senior Research Fellowship. This work used the ARCHER UK National High Performance Computing Service (http://www.archer.ac.uk) via our membership of the UK's HEC Materials Chemistry Consortium, which is funded by EPSRC (EP/L000202, EP/R029431). The authors acknowledge the use of the UCL Legion High Performance Facility (Legion@UCL).

\section{REFERENCES}

(1) Lovley, D. R. Electromicrobiology. Annu. Rev. Microbiol. 2012, 66, 391-409.

(2) Shi, L.; Dong, H. L.; Reguera, G.; Beyenal, H.; Lu, A. H.; Liu, J.; Yu, H. Q.; Fredrickson, J. K. Extracellular electron transfer mechanisms between microorganisms and minerals. Nat. Rev. Microbiol. 2016, 14 (10), 651-662.
(3) Breuer, M.; Rosso, K. M.; Blumberger, J.; Butt, J. N. Multi-haem cytochromes in Shewanella oneidensis MR-1: structures, functions and opportunities. J. R. Soc., Interface 2015, 12 (102), 20141117.

(4) White, G. F.; Edwards, M. J.; Gomez-Perez, L.; Richardson, D. J.; Butt, J. N.; Clarke, T. A. Mechanisms of Bacterial Extracellular Electron Exchange. Adv. Microb. Physiol. 2016, 68, 87-138.

(5) Blumberger, J. Electron transfer and transport through multiheme proteins: recent progress and future directions. Curr. Opin. Chem. Biol. 2018, 47, 24-31.

(6) Pirbadian, S.; Barchinger, S. E.; Leung, K. M.; Byun, H. S.; Jangir, Y.; Bouhenni, R. A.; Reed, S. B.; Romine, M. F.; Saffarini, D. A.; Shi, L.; Gorby, Y. A.; Golbeck, J. H.; El-Naggar, M. Y. Shewanella oneidensis MR-1 nanowires are outer membrane and periplasmic extensions of the extracellular electron transport components. Proc. Natl. Acad. Sci. U. S. A. 2014, 111 (35), 12883-12888.

(7) Wang, F. B.; Gu, Y. Q.; O’Brien, J. P.; Yi, S. M.; Yalcin, S. E.; Srikanth, V.; Shen, C.; Vu, D.; Ing, N. L.; Hochbaum, A. I.; Egelman, E. H.; Malvankar, N. S. Structure of microbial nanowires reveals stacked hemes that transport electrons over micrometers. Cell 2019, 177 (2), 361-369.

(8) Filman, D. J.; Marino, S. F.; Ward, J. E.; Yang, L.; Mester, Z.; Bullitt, E.; Lovley, D. R.; Strauss, M. Cryo-EM reveals the structural basis of long-range electron transport in a cytochrome-based bacterial nanowire. Commun. Biol. 2019, 2, 219.

(9) van Wonderen, J. H.; Li, D. B.; Piper, S. E. H.; Lau, C. Y.; Jenner, L. P.; Hall, C. R.; Clarke, T. A.; Watmough, N. J.; Butt, J. N. Photosensitised multiheme cytochromes as light-driven molecular wires and resistors. ChemBioChem 2018, 19 (20), 2206-2215.

(10) Leung, K. M.; Wanger, G.; El-Naggar, M. Y.; Gorby, Y.; Southam, G.; Lau, W. M.; Yang, J. Shewanella oneidensis MR-1 bacterial nanowires exhibit $p$-type, tunable electronic behavior. Nano Lett. 2013, 13 (6), 2407-2411.

(11) Zacharoff, L. A.; El-Naggar, M. Y. Redox conduction in biofilms: From respiration to living electronics. Curr. Opin. Electrochem. 2017, 4 (1), 182-189.

(12) Garg, K.; Ghosh, M.; Eliash, T.; van Wonderen, J. H.; Butt, J. N.; Shi, L.; Jiang, X. Y.; Zdenek, F.; Blumberger, J.; Pecht, I.; Sheves, M.; Cahen, D. Direct evidence for heme-assisted solid-state electronic conduction in multi-heme c-type cytochromes. Chem. Sci. 2018, 9 (37), 7304-7310.

(13) Kumar, A.; Hsu, L. H. H.; Kavanagh, P.; Barriere, F.; Lens, P. N. L.; Lapinsonniere, L.; Lienhard, J. H.; Schroder, U.; Jiang, X. C.; Leech, D. The ins and outs of microorganism-electrode electron transfer reactions. Nat. Rev. Chem. 2017, 1 (3), 0024.

(14) Kato, S. Biotechnological aspects of microbial extracellular electron transfer. Microbes Environ. 2015, 30 (2), 133-139.

(15) Sasaki, K.; Sasaki, D.; Kamiya, K.; Nakanishi, S.; Kondo, A.; Kato, S. Electrochemical biotechnologies minimizing the required electrode assemblies. Curr. Opin. Biotechnol. 2018, 50, 182-188.

(16) Leys, D.; Meyer, T. E.; Tsapin, A. S.; Nealson, K. H.; Cusanovich, M. A.; Van Beeumen, J. J. Crystal structures at atomic resolution reveal the novel concept of "electron-harvesting" as a role for the small tetraheme cytochrome c. J. Biol. Chem. 2002, 277 (38), 35703-35711.

(17) Blumberger, J. Recent advances in the theory and molecular simulation of biological electron transfer reactions. Chem. Rev. 2015, 115 (20), 11191-11238.

(18) Jiang, X. Y.; Futera, Z.; Ali, M. E.; Gajdos, F.; von Rudorff, G. F.; Carof, A.; Breuer, M.; Blumberger, J. Cysteine linkages accelerate electron flow through tetra-heme protein STC. J. Am. Chem. Soc. 2017, 139 (48), 17237-17240.

(19) Breuer, M.; Rosso, K. M.; Blumberger, J. Electron flow in multiheme bacterial cytochromes is a balancing act between heme electronic interaction and redox potentials. Proc. Natl. Acad. Sci. U. S. A. 2014, 111 (2), 611-616.

(20) Barrozo, A.; El-Naggar, M. Y.; Krylov, A. I. Distinct electron conductance regimes in bacterial decaheme cytochromes. Angew. Chem., Int. Ed. 2018, 57 (23), 6805-6809. 
(21) Jiang, X. Y.; Burger, B.; Gajdos, F.; Bortolotti, C.; Futera, Z.; Breuer, M.; Blumberger, J. Kinetics of trifurcated electron flow in the decaheme bacterial proteins MtrC and MtrF. Proc. Natl. Acad. Sci. U. S. A. 2019, 116 (9), 3425-3430.

(22) Geren, L.; Durham, B.; Millett, F. Use of ruthenium photoreduction techniques to study electron transfer in cytochrome oxidase. Methods Enzymol. 2009, 456, 507-520.

(23) Kokhan, O.; Ponomarenko, N. S.; Pokkuluri, P. R.; Schiffer, M.; Mulfort, K. L.; Tiede, D. M. Bidirectional photoinduced electron transfer in Ruthenium(II)-tris-bipyridyl-modified PpcA, a multi-heme c-type cytochrome from Geobacter sulfurreducens. J. Phys. Chem. B 2015, 119 (24), 7612-7624.

(24) Winkler, J. R.; Gray, H. B. Electron-transfer in rutheniummodified proteins. Chem. Rev. 1992, 92 (3), 369-379.

(25) Ener, M. E.; Gray, H. B.; Winkler, J. R. Hole hopping through tryptophan in cytochrome P450. Biochemistry 2017, 56 (28), 35313538.

(26) Millett, F.; Durham, B. Design of photoactive ruthenium complexes to study interprotein electron transfer. Biochemistry 2002, 41 (38), 11315-11324.

(27) Geren, L.; Hahm, S.; Durham, B.; Millett, F. Photoinduced electron-transfer between cytochrome-c peroxidase and yeast cytochrome-c labeled at Cys-102 with (4-bromomethyl-4'methylbipyridine) $[$ bis(bipyridine) $]$ ruthenium ${ }^{2+}$. Biochemistry 1991, 30 (39), 9450-9457.

(28) Fonseca, B. M.; Saraiva, I. H.; Paquete, C. M.; Soares, C. M.; Pacheco, I.; Salgueiro, C. A.; Louro, R. O. The tetraheme cytochrome from Shewanella oneidensis MR-1 shows thermodynamic bias for functional specificity of the hemes. JBIC, J. Biol. Inorg. Chem. 2009, 14 (3), 375-385.

(29) Greetham, G. M.; Sole, D.; Clark, I. P.; Parker, A. W.; Pollard, M. R.; Towrie, M. Time-resolved multiple probe spectroscopy. Rev. Sci. Instrum. 2012, 83 (10), 103107.

(30) Greetham, G. M.; Burgos, P.; Cao, Q. A.; Clark, I. P.; Codd, P. S.; Farrow, R. C.; George, M. W.; Kogimtzis, M.; Matousek, P.; Parker, A. W.; Pollard, M. R.; Robinson, D. A.; Xin, Z. J.; Towrie, M. ULTRA: A unique instrument for time-resolved spectroscopy. Appl. Spectrosc. 2010, 64 (12), 1311-1319.

(31) Case, D. A. e. a. AMBER 10; University of California: San Francisco, CA, 2008.

(32) Jorgensen, W. L.; Chandrasekhar, J.; Madura, J. D.; Impey, R. W.; Klein, M. L. Comparison of simple potential functions for simulating liquid water. J. Chem. Phys. 1983, 79 (2), 926-935.

(33) Seidel, R.; Faubel, M.; Winter, B.; Blumberger, J. Single-ion reorganization free energy of aqueous $\mathrm{Ru}(\mathrm{bpy})_{3}{ }^{2+/ 3+}$ and $\mathrm{Ru}-$ $\left(\mathrm{H}_{2} \mathrm{O}\right)_{6}^{2+/ 3+}$ from photoemission spectroscopy and density functional molecular dynamics simulation. J. Am. Chem. Soc. 2009, 131 (44), 16127-16137.

(34) Oberhofer, H.; Blumberger, J. Insight into the mechanism of the $\mathrm{Ru}^{2+}-\mathrm{Ru}^{3+}$ electron self-exchange reaction from quantitative rate calculations. Angew. Chem., Int. Ed. 2010, 49 (21), 3631-3634.

(35) Oberhofer, H.; Blumberger, J. Revisiting electronic couplings and incoherent hopping models for electron transport in crystalline C60 at ambient temperatures. Phys. Chem. Chem. Phys. 2012, 14 (40), $13846-13852$.

(36) CPMD, http://www.cpmd.org/, Copyright IBM Corp 19902015, Copyright MPI für Festkörperforschung Stuttgart 1997-2001.

(37) Perdew, J. P.; Burke, K.; Ernzerhof, M. Generalized gradient approximation made simple. Phys. Rev. Lett. 1996, 77 (18), 38653868.

(38) Kalyanasundaram, K. Photophysics, photochemistry and solarenergy conversion with tris(bipyridyl)Ruthenium(II) and its analogs. Coord. Chem. Rev. 1982, 46, 159-244.

(39) Kubas, A.; Hoffmann, F.; Heck, A.; Oberhofer, H.; Elstner, M.; Blumberger, J. Electronic couplings for molecular charge transfer: Benchmarking CDFT, FODFT, and FODFTB against high-level ab initio calculations. J. Chem. Phys. 2014, 140 (10), 104105.

(40) Tipmanee, V.; Oberhofer, H.; Park, M.; Kim, K. S.; Blumberger, $\mathrm{J}$. Prediction of reorganization free energies for biological electron transfer: A comparative study of Ru-modified cytochromes and a 4helix bundle protein. J. Am. Chem. Soc. 2010, 132 (47), 17032-17040.

(41) Blumberger, J.; Lamoureux, G. Reorganization free energies and quantum corrections for a model electron self-exchange reaction: comparison of polarizable and non-polarizable solvent models. Mol. Phys. 2008, 106 (12-13), 1597-1611.

(42) Matyushov, D. V. Protein electron transfer: Dynamics and statistics. J. Chem. Phys. 2013, 139 (2), 025102-025112.

(43) Juris, A.; Balzani, V.; Barigelletti, F.; Campagna, S.; Belser, P.; Vonzelewsky, A. $\mathrm{Ru}(\mathrm{II})$ polypyridine complexes - photophysics, photochemistry, electrochemistry, and chemi-luminescence. Coord. Chem. Rev. 1988, 84, 85-277.

(44) Bettis, S. E.; Hanson, K.; Wang, L.; Gish, M. K.; Concepcion, J. J.; Fang, Z.; Meyer, T. J.; Papanikolas, J. M. Photophysical characterization of a chromophore/water oxidation catalyst containing a layer-by-layer assembly on nanocrystalline $\mathrm{TiO}_{2}$ using ultrafast spectroscopy. J. Phys. Chem. A 2014, 118 (45), 10301-10308.

(45) Wang, L.; Ashford, D. L.; Thompson, D. W.; Meyer, T. J.; Papanikolas, J. M. Watching photoactivation in a $\mathrm{Ru}(\mathrm{II})$ chromophore-catalyst assembly on $\mathrm{TiO}_{2}$ by ultrafast spectroscopy. J. Phys. Chem. C 2013, 117 (46), 24250-24258.

(46) Sun, Q. C.; Mosquera-Vazquez, S.; Daku, L. M. L.; Guenee, L.; Goodwin, H. A.; Vauthey, E.; Hauser, A. Experimental evidence of ultrafast quenching of the ${ }^{3}$ MLCT luminescence in Ruthenium(II) tris-bipyridyl complexes via a ${ }^{3} \mathrm{dd}$ state. J. Am. Chem. Soc. 2013, 135 (37), 13660-13663.

(47) Damrauer, N. H.; Cerullo, G.; Yeh, A.; Boussie, T. R.; Shank, C. V.; McCusker, J. K. Femtosecond dynamics of excited-state evolution in $\left[\mathrm{Ru}(\text { bpy })_{3}\right]^{2+}$. Science 1997, 275 (5296), 54-57.

(48) Kukura, P.; McCamant, D. W.; Mathies, R. A. Femtosecond stimulated Raman spectroscopy. Annu. Rev. Phys. Chem. 2007, 58, 461-488.

(49) Moser, C. C.; Keske, J. M.; Warncke, K.; Farid, R. S.; Dutton, P. L. Nature of biological electron-transfer. Nature 1992, 355 (6363), 796-802.

(50) Winkler, J. R.; Gray, H. B. Electron flow through metalloproteins. Chem. Rev. 2014, 114 (7), 3369-3380.

(51) Wigginton, N. S.; Rosso, K. M.; Lower, B. H.; Shi, L.; Hochella, M. F. Electron tunneling properties of outer-membrane decaheme cytochromes from Shewanella oneidensis. Geochim. Cosmochim. Acta 2007, 71 (3), 543-555.

(52) Byun, H. S.; Pirbadian, S.; Nakano, A.; Shi, L.; El-Naggar, M. Y. Kinetic Monte Carlo simulations and molecular conductance measurements of the bacterial decaheme cytochrome MtrF. ChemElectroChem 2014, 1 (11), 1932-1939.

(53) Harada, E.; Kumagai, J.; Ozawa, K.; Imabayashi, S.; Tsapin, A. S.; Nealson, K. H.; Meyer, T. E.; Cusanovich, M. A.; Akutsu, H. A directional electron transfer regulator based on heme-chain architecture in the small tetraheme cytochrome $c$ from Shewanella oneidensis. FEBS Lett. 2002, 532 (3), 333-337.

(54) Paquete, C. M.; Saraiva, I. H.; Calcada, E.; Louro, R. O. Molecular basis for directional electron transfer. J. Biol. Chem. 2010, 285 (14), 10370-10375.

(55) Kerisit, S.; Rosso, K. M.; Dupuis, M.; Valiev, M. Molecular computational investigation of electron-transfer kinetics across cytochrome-iron oxide interfaces. J. Phys. Chem. C 2007, 111 (30), 11363-11375.

(56) Edwards, M. J.; White, G. F.; Norman, M.; Tome-Fernandez, A.; Ainsworth, E.; Shi, L.; Fredrickson, J. K.; Zachara, J. M.; Butt, J. N.; Richardson, D. J.; Clarke, T. A. Redox linked flavin sites in extracellular decaheme proteins involved in microbe-mineral electron transfer. Sci. Rep. 2015, 5, 11677.

(57) Clarke, T. A.; Edwards, M. J.; Gates, A. J.; Hall, A.; White, G. F.; Bradley, J.; Reardon, C. L.; Shi, L.; Beliaev, A. S.; Marshall, M. J.; Wang, Z. M.; Watmough, N. J.; Fredrickson, J. K.; Zachara, J. M.; Butt, J. N.; Richardson, D. J. Structure of a bacterial cell surface decaheme electron conduit. Proc. Natl. Acad. Sci. U. S. A. 2011, 108 (23), 9384-9389. 